Open Access

\title{
Long term effects of self-determination theory and motivational interviewing in a web-based physical activity intervention: randomized controlled trial
}

\author{
Stijn AH Friederichs ${ }^{*}$, Anke Oenema ${ }^{2}$, Catherine Bolman ${ }^{1}$ and Lilian Lechner ${ }^{1}$
}

\begin{abstract}
Background: Our main objective in the current study was to evaluate the long-term effectiveness (12 months from baseline) of I Move (a web-based computer tailored physical activity intervention, based on self-determination theory and motivational interviewing). To this end, we compared I Move to a web-based computer tailored physical activity intervention based on traditional health behavior theories (Active Plus), and to a no-intervention control group. As a secondary objective, the present study aimed to identify participant characteristics that moderate the long term effects of I Move and Active Plus.

Methods: A randomized controlled trial was conducted, comparing three research conditions: 1) the I Move condition, participants in this condition received I Move; 2) the Active Plus condition, participants in this condition received Active Plus; 3) the control condition; participants in this condition received no intervention and were placed on a waiting list. Main outcome measures were weekly minutes of moderate to vigorous physical activity and weekly days with minimal 30 min of physical activity. All measurements were taken by web-based questionnaires via the study website. Intervention effects were analyzed using multilevel linear regression analyses.

Results: At 12 months from baseline, I Move was found to be effective in increasing weekly minutes of moderate to vigorous physical activity $(E S=.13)$, while Active Plus was not. In contrast, Active Plus was found to be effective in increasing weekly days with $\geq 30$ min PA at 12 months $(E S=.11$ ), while I Move was not. No moderators of the effects of I Move were found.

Conclusions: The results suggest that web-based computer tailored physical activity interventions might best include elements based on both self-determination theory/motivational interviewing and traditional health behavioral theories. To be more precise, it is arguable that the focus of the theoretical foundations, used in new web-based PA interventions should depend on the intended program outcome. In order to draw firm conclusions, however, more research on the effects of self-determination theory and motivational interviewing in web-based physical activity promotion is needed.
\end{abstract}

Trial registration: Dutch Trial Register NTR4129

Keywords: Physical activity, Motivational interviewing, Self-determination theory

\footnotetext{
*Correspondence: stijn.friederichs@ou.nl

'Open University of the Netherlands, Faculty of Psychology and Educational

Sciences, P.O. box 2960, 6401 DL Heerlen, The Netherlands

Full list of author information is available at the end of the article
} provide a link to the Creative Commons license, and indicate if changes were made. The Creative Commons Public Domain Dedication waiver (http://creativecommons.org/publicdomain/zero/1.0/) applies to the data made available in this article, unless otherwise stated. 


\section{Background}

Regular physical activity (PA) is highly beneficial for health, and decreases the risk of many adverse health conditions such as coronary heart disease, type 2 diabetes and breast and colon cancer [1]. Unfortunately, large parts of the world populations are insufficiently physically active [2] thus making the promotion of PA a public health priority [3, 4]. Previous research has shown that intensive and repeated counseling by health care professionals is effective in getting individuals to increase their PA level [5-7]. However, face-to-face PA counseling interventions are often too expensive to be implemented on a population level $[8,9]$.

Web-based computer tailored PA interventions might be a plausible alternative to individual PA counseling [10]. These interventions provide individualized feedback that matches personal characteristics and needs [10-12]. Delivery via the internet makes it possible to reach large numbers of people for relatively low costs $[10,11,13,14]$. Recent meta-analyses show that webbased computer tailored PA interventions are capable of producing modest but significant short-term increases in PA $[15,16]$. However, several studies show that these short-term effects tend to diminish or extinguish as follow-up up time increases $[15,16]$.

To date, web-based computer tailored PA interventions have typically been based on traditional health behavior theories such as social cognitive theory (SCT), self-regulation theory (SRT), the trans-theoretical model (TTM) and the theory of planned behavior (TPB) [12, $15,17]$. Interventions of this type, hereafter referred to as 'traditional interventions', make use of theoretical constructs such as stages of change, modeling, attitude and self-efficacy [15]. Recent research on determinants of sustained PA behavior, however, shows another theoretical construct to be essential: autonomous motivation [18-21]. Substantial evidence suggests that having higher autonomous motivation makes an individual more likely to persist with a PA routine [22]. Although the concept of autonomous motivation does not feature explicitly in SCT, SRT, TTM or TPB, it is central to self-determination theory (SDT) and motivational interviewing (MI) [23, 24]. Applying the principles of SDT and MI in web-based computer-tailored PA interventions could be a promising improvement for these interventions, and could possibly be more effective in promoting sustained PA behavior than traditional web-based computer tailored PA interventions [25].

In order to gain more insight into the effectiveness and feasibility of applying SDT and MI in web-based PA promotion, we systematically developed I Move, a webbased computer tailored PA intervention, grounded in SDT and MI [23, 24, 26]. I Move was found to be effective in significantly increasing PA behavior in the short term (3-6 months after baseline), compared to a nointervention control condition (Friederichs S, Oenema A, Bolman C, Lechner L: Effects of motivational interviewing and self-determination theory in a web-based computer tailored physical activity intervention: a randomized controlled trial, submitted). The short-term effects of I Move on PA behavior were comparable to the short-term effects of Active Plus (a traditional webbased computer tailored PA intervention). Autonomous motivation, however, may be especially important for sustained changes in PA behavior. Differences in effects on PA between I Move and Active Plus could therefore become more pronounced in the long-term. In the current paper, we aim to assess how the 6-month effects of I Move on PA behavior evolve over time (until 12 months from baseline), compared to Active Plus, and compared to a no-intervention control group. First, however, we provide additional background on SDT and MI.

\section{Self-determination theory \& motivational interviewing}

SDT is a comprehensive theory of behavioral motivation $[24,27,28]$, which has proven to be particularly useful in the context of PA research, both for accounting for patterns of PA behavior and for informing the development of interventions for promoting PA [22, 29]. Central to this theory is the difference between autonomous and controlled motivation. Both autonomous and controlled motivation influence behavior, but they each lead to a different outcome, with autonomous motivation leading to greater commitment and long-standing maintenance of behavior $[24,27,28,30]$. SDT posits that individuals are more likely to exhibit autonomous motivation when three basic psychological needs are supported: autonomy (i.e. the need to feel that one can choose one's behaviors), competence (the need to feel competent and confident) and relatedness (the need to feel connected to and understood by others) [24, 27, 28]. Motivational interviewing (MI) is defined as "a collaborative conversation style for strengthening a person's own motivation and commitment to change" [23]. Several researchers have argued that the specific client-centered communication skills used in motivational interviewing (MI) can be used to support client's basic psychological needs [29, 31-33].

In recent years, numerous PA counseling interventions that combine the theoretical framework of SDT with the practical strategies from MI have been developed and evaluated in randomized controlled trials [19, 34-43]. In general, these interventions are effective in promoting a sustained increase in PA. As discussed above, however, face-to-face PA counseling interventions are often too expensive to be implemented on a large scale [8,9]. Web-based computer tailored PA interventions grounded in SDT and using the communication style and principles from MI, may be promising for promoting sustained PA 
behavior on the population level at relatively low costs [25]. To our knowledge, however, no studies have yet evaluated the long term effects of SDT and MI in web-based PA promotion.

\section{Research objectives}

Our main objective in the current study was to evaluate the long-term effectiveness (12 months from baseline) of I Move (a web-based computer tailored PA intervention aimed at adults, based on SDT and MI). To this end, we compared I Move to a traditional web-based computer tailored PA intervention (Active Plus), and to a nointervention control group. It was hypothesized that at 12 months from baseline, the effects of I Move would be better retained compared to the effects of Active Plus.

Moderator analyses can identify the participant subgroups in which an intervention exerts the greatest effects, enabling a more in-depth view on impact of the intervention. Such results can potentially yield recommendations for future intervention adaptation and development [44]. Previous studies on tailored PA interventions have shown that participant characteristics (such as age and gender and the intention to be sufficiently physically active) can moderate the effects of tailored PA interventions [45-52]. The short-term effects of I Move on PA at 6 months were moderated by gender, age and relational status; the effects of I Move were more pronounced in male participants, participants younger than 47 , and participants who were single. Therefore, as a secondary objective the present study aimed to identify participant characteristics that moderate the long term effects of I Move and Active Plus.

\section{Method}

For the purpose of this study, we conducted a randomized controlled trial (RCT), which was registered with the Dutch Trial Register (NTR4129).

\section{Participants and procedure}

Individuals between 18 and 70 years old, who did not have a condition that seriously impedes their ability to be physically active, who did not take part in one of the pilot studies [53, 54], and who were less physically active than 5 days per week for $60 \mathrm{~min}$ per day were considered for participation [26]. A power calculation $(E S=.25$; power $=.80$ ), showed that data from 600 participants would be needed for this study. Based on an expected dropout of 40-70\% $[55,56]$, we needed to enroll 2,000 respondents in the study.

The study procedure and flow of participants is shown in Fig. 1. From September to December 2013, participants were recruited by means of advertisements (containing a link to the study website) in national newspapers, social media, and via an online panel. At the study website, individuals were given the option to participate in the study by clicking on the "I want to participate" button. After passing through the inclusion questions and giving informed consent, participants were randomized into one of the three research conditions $(1: 1: 1)$ by means of a digital randomizer built into the website, and were asked to complete the baseline questionnaire. The three research conditions in this study are: 1) the I Move condition; participants in this condition received I Move, a web-based computer tailored PA intervention based on MI and SDT $[26], 2)$ the Active Plus condition; participants in this condition received Active Plus, a traditional web-based computer tailored PA intervention, based on traditional health behavioral theories such as TPB, SCT, SRT and TTM $[57,58]$ and 3) the control condition, a waiting list control group.

Measurements were taken at baseline, and at 3, 6 and 12 months from baseline. All measurements were taken by web-based questionnaires via the study website. Participants from the two intervention conditions were also asked to complete a questionnaire at 6 weeks from baseline. This questionnaire contained questions that are used to tailor the intervention content, as well as questions on process evaluation. In order to decrease attrition, 10 prizes of $€ 50$ were raffled off among those participants who completed each questionnaire [59]. Among those participants who completed all questionnaires, two tablet computers were raffled off.

\section{Ethics, consent and permissions}

The Medical Ethics Committee of Atrium-Orbis-Zuyd approved the RCT. Before being able to participate in the study, all potential participants were asked to give informed consent.

\section{Interventions}

I Move is a web-based computer tailored PA intervention, aimed at increasing and maintaining PA among adults [26]. The intervention is based on the theoretical insights of SDT and the practical applications of MI. Since developing interventions in a systematically planned way increases the likelihood of effectiveness [60], we used the Intervention Mapping protocol [61] to develop I Move.

I Move entails four automated text-based sessions. During these sessions, participants answer several questions (either by typing in their answer or choosing their answer from a list). In between those questions they receive tailored feedback text messages and tailored follow-up questions. As such, a motivational dialogue is simulated between the intervention and the participant. Alongside the text-based sections, at regular times during the intervention, participants are offered the option of watching short videos (starring a program host, a PA- 


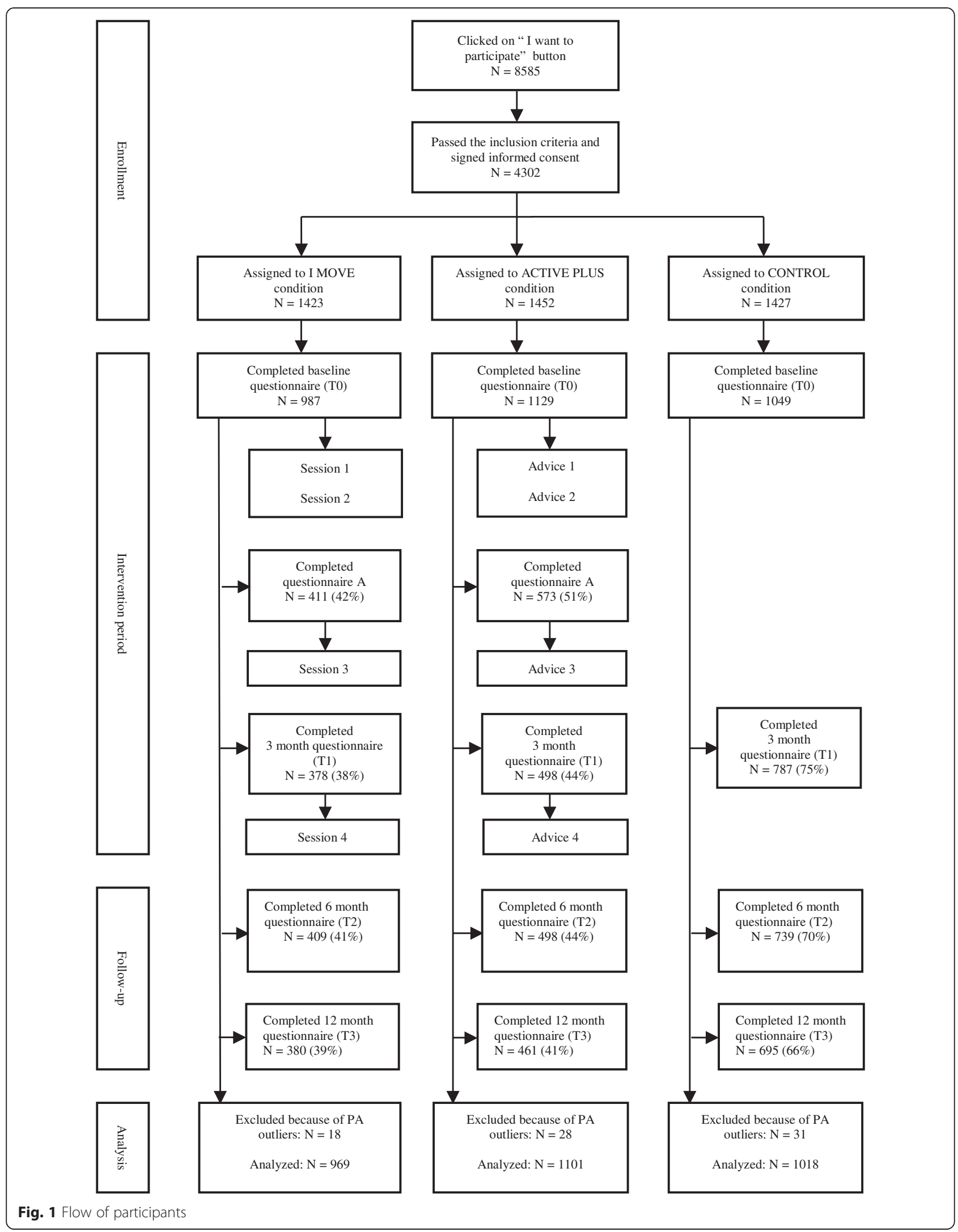


expert and four allegedly former intervention participants). Session 1 starts with an introduction, and after that several topics such as the participant's current PA, how important he/she thinks it is to increase his/her PA level, and how confident he/she is with regards to becoming more physically active are discussed. Participants can choose to make an action plan to become more active. Three weeks and six weeks later, participants receive an email invitation for session 2 and 3 , respectively. Session 2 and 3 address in more detail the topics of perceived importance of and perceived confidence in becoming more physically active. Participants are given the opportunity to evaluate and adjust their plans, and to formulate coping plans. During session 3, participants receive feedback on their current PA level as compared to their PA level at baseline. Three months after session 1, participants receive an email invitation for session 4. In this session, participants are given the option to choose which parts of the session they want to go through (ipsative feedback on PA, long-term motivation and confidence). The day after having completed an intervention session, participants receive a PDF file by email, containing a summary of the session content. For more detailed information on the content and basis of I Move, please see the separate design paper [26].

Active Plus is a systematically developed, theory- and evidence-based web-based computer tailored PA intervention $[57,58]$. This intervention is predominantly founded on traditional health behavior change theories such as TPB, SCT, SRT and TTM. The original Active Plus intervention encompasses three rounds of tailored advice $[57,58]$. In order to make Active Plus optimally comparable to I Move (which contains four intervention moments), a fourth tailored advice was added to Active Plus. Furthermore, since Active Plus was originally designed for individuals over 50 years of age, we adapted the content slightly in order to make it appropriate for the general adult population.

An important difference between I Move and Active Plus concerns the degree of interactivity. In Active Plus, participants are first asked to complete a questionnaire on all the relevant psychological constructs, and then they the complete advice. I Move is designed to simulate a conversation with the participant by means of an interactive question-feedback approach. Hence, the participant is asked to actively participate in the intervention by responding to the questions, and reading the feedback messages. In addition, several other differences between the interventions exist, many of which are related to the fact that I Move provides more autonomy support. For example, before being provided with information on PA, participants in I Move are first asked whether they would like to read some more about the beneficial effects of PA, while in Active Plus no permission is asked, and information is simply provided. In Fig. 2, the most important similarities and differences between the interventions are summarized.

\section{Questionnaire \\ Demographics}

At baseline, age, gender, weight and height (combined to $\mathrm{BMI}$ ), relational status and highest completed educational level were assessed. Educational level was categorized into high (higher vocational school or university level) and low to medium (elementary education, medium general secondary education, preparatory vocational school, lower vocational school, higher general secondary education, preparatory academic education, and medium vocational school), according to the Dutch educational system.

\section{PA intention}

As intention to become sufficiently active can be an important predictor of dropout in web-based PA interventions [56], this was measured at baseline. Intention to become sufficiently active was measured with 3 items (e.g. 'Are you planning to be sufficiently physically active?' Definitely not (1) - Yes, definitely (10)). Participants were informed that sufficient physical activity is at least $30 \mathrm{~min}$ of moderate-intensity PA at least 5 days a week.

\section{PA level}

PA behavior was measured at baseline, 3, 6 and 12 months using the validated self-administered Dutch Short Questionnaire to Assess Health Enhancing Physical Activity (SQUASH) [62]. All questions in the SQUASH were asked for a typical week in the past month. Although objective observation might be more accurate, self-report is often the most feasible method when assessing PA in large-scale studies because of the convenience and low costs [63]. Compared to self-report, measuring PA levels with accelerometers is rather intrusive, which does not fit well with the accessible nature of a web-based intervention.

Total weekly minutes of moderate to vigorous PA (MVPA) was calculated by multiplying the frequency (how many days per week), and duration (how many hours and minutes per day) of leisure and transport walking, leisure and transport cycling, sports, gardening, household chores and odd jobs performed with moderate or vigorous intensity. The relative validity $\left(r_{\text {spearman }}=0.45\right.$; $95 \% \mathrm{CI}=0.17-0.66)$ and reproducibility $\left(r_{\text {spearman }}=0.58\right.$; $95 \% \mathrm{CI}=0.36-0.74)$ of the SQUASH are reasonable for the general adult population [65].

Total weekly days with more than 30 min PA were measured by a single item: 'How many days per week are you, in total, moderately physically active by 


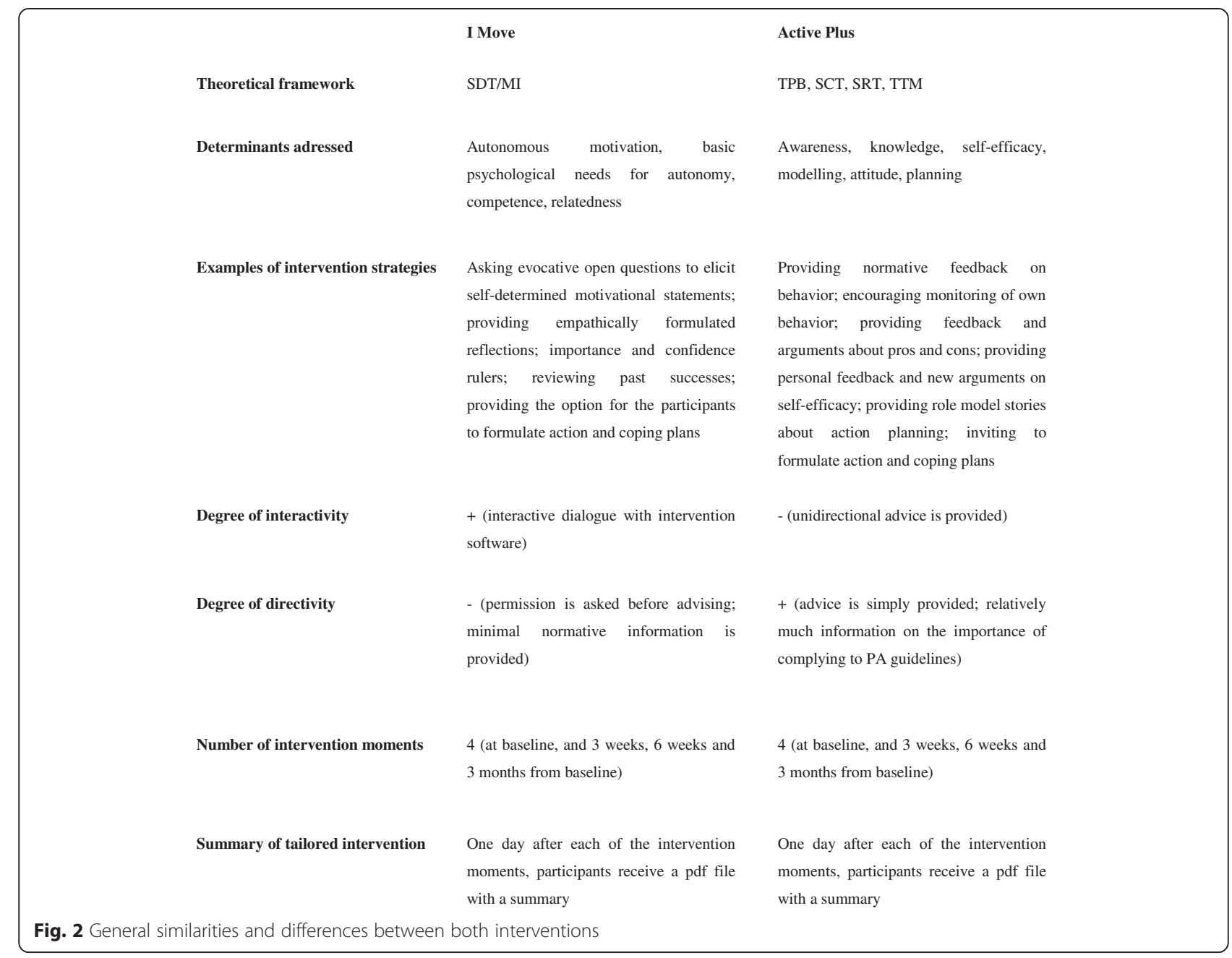

undertaking, for example, brisk walking, cycling, chores, gardening, sports, or other physical activities for at least 30 min?' Prior research provided support for the validity and reliability of single-item self-reports of PA [64, 65] and several studies found the single item PA measure to be among the most accurate PA questionnaires, when compared to accelerometer output $[66,67]$.

\section{Statistical analysis}

All analyses were conducted using SPSS version 22. As instructed by the SQUASH manual, participants who reported over 6,720 min of PA per week were excluded from all analyses because being physically active more than $16 \mathrm{~h}$ per day for 7 days per week was assumed to be impossible [62].

Pearson's correlation was calculated between the baseline values of weekly minutes of MVPA and weekly days with more than 30 min PA. Chi-square tests and one-way analyses of variance (ANOVAs) were conducted to assess potential baseline differences among the research conditions. Logistic regression analyses were performed to identify predictors of dropout at the 12-month questionnaire.

\section{Main outcome analyses}

First, actual PA values (mean and SD) were calculated for each research condition at each timepoint. To evaluate the effects of both interventions on PA, multilevel linear regression analyses with two levels: time was nested within participant. Research condition was coded into two dummy variables, dummyIMOVE and dummyACTIVEPLUS, using the control condition as reference. Separate analyses were conducted for both PA outcome measures (total weekly minutes of MVPA, and weekly days with $\geq 30 \mathrm{~min} P A)$. In both analyses, time, dummyIMOVE, dummyACTIVEPLUS, dummyIMOVE* time and dummyACTIVEPLUS*time were entered as independent variables. Variables included as covariates were: baseline PA value (minutes and days), gender, age, educational level, relational status, BMI and baseline intention to be sufficiently physically active. To correct 
for bias because of selective drop-out, analyses were conducted using the whole dataset, including missing data (intention-to-treat). Conducting multilevel analyses on an incomplete dataset including missing data has been shown to give better estimations than using multiple imputation [68]. Due to the flexible treatment of the time predictor, multilevel analyses can make use of all available data in the estimation of model parameters. As such, research participants with only baseline data can be included in an analysis and contribute to the estimation of model parameters [68]. Aside from the intention-to-treat analyses, completers-only analyses were conducted (including only those participants who provided 12 month PA data).

Cohen's $d$ effect sizes (ESs) were computed for both measurement moments (6 months from baseline and 12 months from baseline) based on the unstandardized regression coefficients and the pooled standard deviation of the outcome measure (at 6 months from baseline and 12 months from baseline, respectively) [69]. Effect sizes of $0.15,0.20$ and 0.25 , respectively, were considered small, medium and large [70].

\section{Moderator analyses}

In order to assess whether the long-term effects of both interventions on PA were more pronounced in specific subgroups of participants, additional moderator analyses were conducted. In these moderator analyses, only the 12-month follow-up measurements were included. Interaction terms between the intervention dummies and gender, age, educational level, relational status, BMI and intention to be sufficiently physically active were assessed. Separate moderation analyses were performed for each of the user characteristics. If an interaction term had a $p$-value $<.1$ this interaction was decomposed (using a median split in the case of a continuous variable) and subgroup analyses were performed [71-75].

\section{Results}

In Fig. 1, an overview of the flow of participants in the study is presented. A significant correlation was found between baseline values of weekly minutes of MVPA and weekly days with more than 30 min PA ( $\mathrm{r}$.214; $p<.001)$. As shown in Table 1 , no baseline differences on key characteristics were found between the three study conditions. Dropout analysis showed that the lower participants' age $(\mathrm{B}=0.018 \pm 0.003 ; p<.001)$ and the lower their intention to be sufficiently physically active $(B=0.090 \pm$ $0.022 ; p<.001)$, the less likely they were to complete the 12 month PA questionnaire. In addition, the more weekly minutes of MVPA reported at baseline $(\mathrm{B}<0.001 \pm 0.000$; $p<.001)$ and the fewer weekly days with $\geq 30 \mathrm{~min}$ PA reported at baseline $(\mathrm{B}=0.080 \pm 0.024 ; p=.001)$, the less likely participants were to complete the 12 month PA questionnaire. Finally, participants were less likely to complete the 12 month PA questionnaire if they were married or living together $(\mathrm{OR}=1.32$; $95 \% \mathrm{CI}=1.11-1.57$; $p=.002)$, if they had a lower education level $(\mathrm{OR}=1.22$; $95 \% \mathrm{CI}=1.05-1.43 ; p=.011)$ and if they were randomized in one of the intervention conditions $\left(\mathrm{OR}_{\mathrm{IMove}}=3.28\right.$; $95 \% \mathrm{CI}=2.72-3.95 ; p<.001 ; \mathrm{OR}_{\text {ActivePlus }}=3.00 ; 95 \%$ $\mathrm{CI}=2.51-3.60 ; p<.001)$. These predictors of dropout were included in the effect analyses as covariates.

\section{Intervention effects}

Table 2 shows the actual PA values for the three research conditions at all time points. In Table 3 , the results of the intention-to-treat and completers-only analyses are shown. As can be seen in this table, the results from intention-to-treat and the completers-only analyses are highly similar. The results will be further discussed below.

\section{Intervention effects on weekly minutes of MVPA: intention-to-treat}

In these analyses, I Move had a significant effect on weekly minutes of MVPA at 6 months from baseline;

Table 1 Baseline characteristics

\begin{tabular}{|c|c|c|c|c|}
\hline & I Move & Active Plus & No intervention & $F / X^{2}(d f=2)$ \\
\hline & $n=969$ & $n=1101$ & $n=1018$ & \\
\hline Gender: \% male & $30.2 \%$ & $31.4 \%$ & $30.8 \%$ & 0.34 \\
\hline Age & $44.99 \pm 13.12$ & $45.25 \pm 12.67$ & $44.48 \pm 12.69$ & 0.97 \\
\hline Relational status: \% married/living together & $74.4 \%$ & $74.3 \%$ & $73.9 \%$ & 0.09 \\
\hline Education: \% high education & $63.2 \%$ & $61.4 \%$ & $61.0 \%$ & 1.11 \\
\hline BMl & $26.16 \pm 4.78$ & $26.06 \pm 5.22$ & $25.81 \pm 4.51$ & 1.33 \\
\hline Physical activity, weekly minutes & $510 \pm 573$ & $479 \pm 541$ & $501 \pm 554$ & 0.89 \\
\hline Physical activity, weekly days & $3.09 \pm 1.70$ & $3.09 \pm 1.65$ & $3.14 \pm 1.70$ & 0.16 \\
\hline Intention to be sufficiently physically active & $7.07 \pm 1.89$ & $7.16 \pm 1.81$ & $7.16 \pm 1.88$ & 0.71 \\
\hline
\end{tabular}


Table 2 Absolute PA levels at baseline, 6 months and 12 months

\begin{tabular}{|c|c|c|c|}
\hline \multicolumn{4}{|c|}{ Weekly minutes of MVPA } \\
\hline & Baseline & 6 months & 12 months \\
\hline I Move & $510 \pm 573$ & $640 \pm 647$ & $618 \pm 625$ \\
\hline Active Plus & $479 \pm 541$ & $637 \pm 665$ & $540 \pm 501$ \\
\hline Control & $501 \pm 554$ & $558 \pm 581$ & $536 \pm 512$ \\
\hline \multicolumn{4}{|c|}{ Weekly days with $\geq 30$ min PA } \\
\hline & Baseline & 6 months & 12 months \\
\hline I Move & $3.09 \pm 1.70$ & $4.06 \pm 1.88$ & $4.02 \pm 1.86$ \\
\hline Active Plus & $3.09 \pm 1.65$ & $4.35 \pm 1.81$ & $4.04 \pm 2.02$ \\
\hline Control & $3.13 \pm 1.70$ & $3.73 \pm 1.89$ & $3.84 \pm 1.88$ \\
\hline
\end{tabular}

participants from the I Move condition increased their weekly minutes of MVPA by $76 \mathrm{~min}$, compared to the control condition $(\mathrm{B}=76.22 ; p=.015 ; \mathrm{ES}=.13)$. Active Plus also achieved a significant effect on this outcome at 6 months; participants from the Active Plus condition increased their weekly minutes of MVPA by $87 \mathrm{~min}$, compared to the control condition $(\mathrm{B}=87.15 ; p=.003$; $E S=.14)$. The effects of both interventions on weekly minutes of MVPA at 6 months did not differ significantly from each other $(\mathrm{B}=-10.94 ; p=.745$; $\mathrm{ES}=-.02)$. At 12 months from baseline, I Move had a significant effect on weekly minutes of MVPA; participants from the I Move condition increased their weekly minutes of MVPA by $71 \mathrm{~min}$, compared to the control condition $(\mathrm{B}=70.65 ; p=.030 ; \mathrm{ES}=.13)$. The Active Plus condition did not have a significant effect on this outcome at 12 months $(\mathrm{B}=17.54 ; p=.576$; $\mathrm{ES}=.03)$. However, I Move was not significantly more effective in increasing weekly minutes of MVPA at 12 months, compared to Active Plus $(\mathrm{B}=53.11 ; p=.132 ; \mathrm{ES}=.09)$.

\section{Intervention effects on weekly minutes of MVPA: completers-only}

In these analyses, I Move had a significant effect on weekly minutes of MVPA at 6 months from baseline; participants from the I Move condition increased their weekly minutes of MVPA by $96 \mathrm{~min}$, compared to the control condition $(\mathrm{B}=95.92 ; p=.004 ; \mathrm{ES}=.17)$. Active Plus also achieved a significant effect on this outcome at 6 months; participants from the Active Plus condition increased their weekly minutes of MVPA by $90 \mathrm{~min}$, compared to the control condition $(\mathrm{B}=90.14 ; p=.005$; $E S=.18)$. The effects of both interventions on weekly minutes of MVPA at 6 months did not differ significantly from each other $(\mathrm{B}=5.77 ; p=.875 ; \mathrm{ES}=.01)$. At 12 months from baseline, I Move had a significant effect on weekly minutes of MVPA; participants from the I Move condition increased their weekly minutes of MVPA by $78 \mathrm{~min}$, compared to the control condition ( $\mathrm{B}=78.16 ; p=.015 ; \mathrm{ES}=.13$ ). The Active Plus condition did not have a significant effect on this outcome at 12 months $(\mathrm{B}=18.92 ; p=.531 ; \mathrm{ES}=.03)$. However, I Move was not significantly more effective in increasing weekly minutes of MVPA at 12 months, compared to Active Plus $(\mathrm{B}=59.24 ; p=.089 ; \mathrm{ES}=.09)$.

\section{Intervention effects on weekly days with $\geq 30$ min PA: intention-to-treat}

In these analyses, I Move had a significant effect on weekly days with $\geq 30$ min PA at 6 months from baseline; participants from the I Move condition increased their weekly days with $\geq 30 \mathrm{~min}$ PA by 0.3 days, compared to the control group $(\mathrm{B}=0.32 ; p=.001 ; \mathrm{ES}=.17)$. The Active Plus condition also achieved a significant effect on this outcome at 6 months; participants from the Active Plus condition increased their weekly days with $\geq$

Table 3 Intervention effects on weekly minutes of MVPA and weekly days with $\geq 30$ minutes PA

\begin{tabular}{|c|c|c|c|c|c|c|c|c|c|c|c|c|}
\hline & \multicolumn{6}{|c|}{ Intention-To-Treat } & \multicolumn{6}{|c|}{ Completers-Only } \\
\hline & \multicolumn{6}{|c|}{ Weekly minutes of MVPA } & \multicolumn{6}{|c|}{ Weekly minutes of MVPA } \\
\hline & B & $p$ & ES & B & $p$ & ES & B & $p$ & ES & B & $p$ & ES \\
\hline Differences in change & \multicolumn{3}{|c|}{6 months after baseline } & \multicolumn{3}{|c|}{12 months after baseline } & \multicolumn{3}{|c|}{6 months after baseline } & \multicolumn{3}{|c|}{12 months after baseline } \\
\hline IMOVE vs CONTROL & 76.22 & .015 & .13 & 70.65 & .030 & .13 & 95.92 & .004 & .17 & 78.16 & .015 & .13 \\
\hline ACTIVEPLUS vs CONTROL & 87.15 & .003 & .14 & 17.54 & .567 & .03 & 90.14 & .005 & .18 & 18.92 & .531 & .03 \\
\hline \multirow[t]{3}{*}{ IMOVE vs ACTIVE PLUS } & -10.94 & .745 & -.02 & 53.11 & .132 & .09 & 5.77 & .875 & .01 & 59.24 & .089 & .09 \\
\hline & \multicolumn{6}{|c|}{ Weekly days with $\geq 30$ min PA } & \multicolumn{6}{|c|}{ Weekly days with $\geq 30$ min PA } \\
\hline & B & $p$ & ES & B & $p$ & ES & B & $p$ & ES & B & $p$ & ES \\
\hline Differences in change & \multicolumn{3}{|c|}{6 months after baseline } & \multicolumn{3}{|c|}{12 months after baseline } & \multicolumn{3}{|c|}{6 months after baseline } & \multicolumn{3}{|c|}{12 months after baseline } \\
\hline IMOVE vs CONTROL & 0.32 & .001 & .17 & 0.16 & .110 & .09 & 0.32 & .002 & .17 & 0.16 & .112 & .09 \\
\hline ACTIVEPLUS vs CONTROL & 0.60 & $<.001$ & .32 & 0.22 & .023 & .11 & 0.62 & $<.001$ & .32 & 0.22 & .020 & .12 \\
\hline IMOVE vs ACTIVE PLUS & -0.28 & .006 & -.15 & -0.05 & .615 & -.03 & -0.30 & .009 & -.15 & -0.06 & .577 & -.03 \\
\hline
\end{tabular}


30 min PA by 0.6 days, compared to the control group $(\mathrm{B}=0.60 ; p<.001 ; \mathrm{ES}=.32)$. At 6 months, the effect of Active Plus on weekly days with $\geq 30$ min PA was significantly higher than the effect of I Move; participants from the Active Plus condition increased their weekly days with $\geq 30$ min PA by 0.3 days, compared to participants from the I Move condition $(\mathrm{B}=0.28 ; p=.006 ; \mathrm{ES}=.15)$. At 12 months from baseline, I Move did not have a significant effect on weekly days with $\geq 30$ min $\mathrm{PA}$ ( $\mathrm{B}=$ $0.16 ; p=.110$; ES = .09). The Active Plus condition had a significant effect on this outcome at 12 months; participants from the Active Plus condition increased their weekly days with $\geq 30 \mathrm{~min}$ PA by 0.2 days, compared to the control condition $(\mathrm{B}=0.22 ; p=.023 ; \mathrm{ES}=.11)$. However, Active Plus was not significantly more effective in increasing weekly days with $\geq 30 \mathrm{~min} P A$ at 12 months, compared to I Move $(\mathrm{B}=0.05 ; p=.615$; $\mathrm{ES}=.03)$.

\section{Intervention effects on weekly days with $\geq 30 \mathrm{~min} P A$ : completers-only}

In these analyses, I Move had a significant effect on weekly days with $\geq 30$ min PA at 6 months from baseline; participants from the I Move condition increased their weekly days with $\geq 30$ min PA by 0.3 days, compared to the control group $(\mathrm{B}=0.32 ; p=.001 ; \mathrm{ES}=.17)$. The Active Plus condition also achieved a significant effect on this outcome at 6 months; participants from the Active Plus condition increased their weekly days with $\geq$ 30 min PA by 0.6 days, compared to the control group $(\mathrm{B}=0.62 ; p<.001 ; \mathrm{ES}=.32)$. At 6 months, the effect of Active Plus on weekly days with $\geq 30 \mathrm{~min}$ PA was significantly higher than the effect of I Move; participants from the Active Plus condition increased their weekly days with $\geq 30$ min PA by 0.3 days, compared to participants from the I Move condition $(\mathrm{B}=0.30 ; p=.009$; $\mathrm{ES}=.15)$. At 12 months from baseline, I Move did not have a significant effect on weekly days with $\geq 30$ min $\mathrm{PA}(\mathrm{B}=0.16$; $p=.112$; ES =.09). The Active Plus condition had a significant effect on this outcome at 12 months; participants from the Active Plus condition increased their weekly days with $\geq 30 \mathrm{~min}$ PA by 0.2 days, compared to the control condition ( $\mathrm{B}=0.22 ; p=.020 ; \mathrm{ES}=.12)$. However, Active Plus was not significantly more effective in increasing weekly days with $\geq 30 \mathrm{~min}$ PA at 12 months, compared to I Move $(\mathrm{B}=0.06 ; p=.577 ; \mathrm{ES}=.03)$.

\section{Moderators}

Age moderated the 12 month effect of Active Plus on weekly days with $\geq 30 \mathrm{~min}$ PA $(p=.040)$. Active Plus was more effective in increasing days with $\geq 30 \mathrm{~min} P A$ in participants aged $47-70(\mathrm{~B}=0.368 ; p=.008 ; \mathrm{ES}=.19)$ than in participants aged $18-46(\mathrm{~B}=0.077 ; p=.583$; $\mathrm{ES}=.04)$. No additional significant moderators of the intervention effects were found.

\section{Discussion}

At 12 months from baseline, I Move was found to be effective in increasing weekly minutes of MVPA (ES $=.13$; $p=.030)$, while Active Plus was not $(E S=.03 ; p=.567)$. In contrast, Active Plus was found to be effective in increasing weekly days with $\geq 30 \mathrm{~min} P A$ at 12 months $(E S=.11$; $p=.023)$, while I Move was not $(\mathrm{ES}=.09 ; p=.110)$.

The difference between the 12-month effects of the interventions on weekly minutes of MVPA was not statistically significant $(\mathrm{ES}=.09 ; p=.132)$. However, this difference (about one hour of weekly MVPA) might still be of practical importance [56]. At 6 months from baseline, both interventions yielded a comparable effect on weekly minutes of MVPA per week, while at 12 months from baseline the effect of Active Plus had mostly disappeared $(E S=.03 ; p=.567)$, and the positive effect of I Move was sustained ( $\mathrm{ES}=.13 ; p=.030$ ). Although more evidence is needed in order to draw firm conclusions, this trend might be supportive for the use of SDT and MI in web-based CT in order to achieve maintained PA increase. The client-centered approach, as operated in I Move, may have prompted participants to adopt PA behavior for self-determined reasons. As discussed earlier, autonomous motivation facilitates long-standing maintenance of behavior which may partly explain the long-term effectiveness of I Move on this outcome [24, 27, 28, 30]. Then again, the 12 month effect of I Move on weekly minutes of MVPA is not overwhelming. The long-term effect size of the I Move intervention on this outcome was .13 (9 months after the end of the intervention), while in a meta-review on web-based PA interventions, the overall mean effect was .11. (6 months after the end of the intervention) [15]. Therefore, I Move may need to be further improved in order to optimize its long-term intervention effect.

No statistically significant differences were found for the interventions with regard to weekly days with $\geq$ 30 min outcome at 12 months $(\mathrm{ES}=.03 ; p=.615)$. Even so, Active Plus was effective in increasing weekly days with $\geq 30$ min PA (ES $=.11 ; p=.023)$, while I Move was not $(E S=.091 ; p=.110)$. This may be related to the fact that I Move does not provide much information on PA guidelines. According to the principles of SDT and MI, participants in I Move were encouraged to set their own PA norms/goals (which are not necessarily in line with the PA guidelines).

Additional moderator analyses showed that the longterm effects of I Move were not moderated by any participant characteristics; this is supportive of the degree and quality of tailoring in this intervention. The absence of any effect moderators indicates that I Move probably can be effective in increasing weekly minutes of MVPA in different subgroups; for instance in participants with different levels of education, and in different age groups. 
Active Plus was found to be more effective in increasing days with $\geq 30$ min PA in participants aged $47-70$ than in participants aged 18-46. This finding might be explained by the fact that Active Plus was originally designed for individuals over 50 years. The intervention content was adapted in order to make it suitable for the general adult population $[57,58]$. However it is possible that the intervention was still more appealing and motivating for older participants.

\section{Strengths and limitations}

The study reported in this paper is the first to examine the long-term effects of a web-based PA intervention based on SDT and MI. Strengths of this study include the strong randomized controlled design with a large sample size, and no differences between the study conditions at baseline. In addition, self-reported physical activity was measured using a validated measurement instrument [62].

Despite these strengths, the study has some limitations that should be acknowledged. First, although we did our best to develop I Move as congruent as possible to MI and SDT, important differences exist between I Move and MI or SDT-based counseling in a face-to-face context. For instance, compared to I Move, a real human counselor is better able to convey empathy and to react to very subtle expressions of motivation. This leaves room for improvement and further development. In the future, more sophisticated techniques may be able to improve the ability of web-based PA interventions to respond empathically. Second, the fact that the interventions in our studies differ from each other with regard to both theoretical basis and degree of interactivity represents a potential methodological weakness. One could argue, however, that using an interactive approach, as was done for the I Move intervention, is inherent to developing an intervention based on MI and SDT, while this is less obvious when working with traditional health behavioral theories. Still, it would be relevant for future studies on tailored interventions to assess the influence of theoretical framework and degree of interactivity separately. Third, the attrition was considerable. Unfortunately, attrition is very common in studies on eHealth and web-based interventions [76]. Attrition was higher in the intervention conditions compared to the control condition. This is in line with the findings from a recent review on differential attrition in health behavior change interventions [77]. In this study, we aimed to handle the missing data in the most accurate way possible by conducting the main analyses using multilevel linear regression [68]. Indeed, applying multilevel analyses to an incomplete dataset has been shown to give better estimations than using multiple imputation [68]. Fourth, the results of this study may be influenced by selective drop- out (e.g., younger participants dropped out more frequently than did older participants). By including all drop-out predictors in the regression analyses as covariates, and by analyzing the total dataset including missing values, we aimed to account for selective drop-out as much as possible [68]. Fifth, it should be noted that female and highly educated participants were overrepresented in the research population. By conducting moderator analyses, however, we aimed to evaluate whether gender, educational level, and other individual participant characteristics influenced intervention outcomes; we found this not to be the case for I Move. Finally, PA behavior was assessed using self-report questionnaires and although the SQUASH has reasonable reproducibility and relatively good validity [62] a risk remains that the data were subject to biases, for example over-estimation of PA or socially desirable responding $[78,79]$. In our study, there clearly was over-reporting of PA behavior (at baseline, participants reported to be physically active for $\pm 500 \mathrm{~min}$ per week). However, since overreporting was present in all three research condition (including the control condition), it was possible to assess changes in PA behavior over time in a reliable way. Still, future studies on web-based PA interventions should include a more objective measure of PA behavior [80, 81]. Using a more elaborate PA measure would allow to better distinguish between PA at weekdays and PA at weekend days, which could provide useful information on PA patterns throughout the week. However, assessing PA with even more details and additional questions could also result in even more over reporting of PA.

\section{Conclusions}

The present study is the first to evaluate SDT and MI in a web-based computer tailored PA intervention. In this study, I Move was effective in increasing weekly minutes of MVPA at 12 months from baseline, while the effect of Active Plus on this outcome disappeared. This finding provides support for the use of SDT and MI in webbased computer tailored PA interventions. However, Active Plus was found to be effective in increasing weekly days with $\geq 30 \mathrm{~min}$ PA at 12 months, while I Move was not. Together these results suggest that web-based computer tailored PA interventions might best include elements based on both SDT/MI and traditional health behavioral theories. To be more precise, it is arguable that the focus of the theoretical foundations, used in new web-based PA interventions should depend on the intended program outcome. If the intended program outcome is to get individuals to comply with PA guidelines, an emphasis on traditional health behavioral theories might be most suitable. If the intended program outcome is to increase overall PA behavior (without taking into account PA guidelines), making strong use of 
MI and SDT might be more appropriate. However, in order to draw firm conclusions, more research should be done on the effects of SDT and MI in web-based PA promotion. Future research should also assess the working mechanism underpinning the long-term effects of this type of intervention, and whether or not these effects are mediated by an increase in autonomous motivation.

\section{Abbreviations \\ ANOVA: Analysis of variance; ES: Effect size; MI: Motivational interviewing; MVPA: Moderate to vigorous physical activity; PA: Physical activity; RCT: Randomized controlled trial; SCT: Social cognitive theory; SDT: Self- determination theory; SRT: Self-regulation theory; TPB: Theory of planned behavior; TTM: Trans-theoretical model.}

\section{Competing interests}

The authors declare that they have no competing interests.

\section{Authors' contributions}

$A O, C B$ and $L L$ designed and wrote the original proposal. SF, AO, CB and $L L$ developed the intervention. SF significantly contributed to writing this article. $\mathrm{AO}, \mathrm{CB}$ and $\mathrm{LL}$ were involved in revising the manuscript critically. All authors read and approved the final manuscript.

\section{Acknowledgements}

The study was funded by The Netherlands Organization for Health Research and Development (ZonMw, 200120007).

\section{Author details}

'Open University of the Netherlands, Faculty of Psychology and Educational Sciences, P.O. box 2960, 6401 DL Heerlen, The Netherlands. ${ }^{2}$ Department of Health Promotion, Maastricht University, P.O. Box 616, 6200 MD Maastricht, The Netherlands.

\section{Received: 9 March 2015 Accepted: 5 August 2015}

Published online: 18 August 2015

\section{References}

1. Lee IM, Shiroma EJ, Lobelo F, Puska P, Blair SN, Katzmarzyk PT. Effect of physical inactivity on major non-communicable diseases worldwide: an analysis of burden of disease and life expectancy. Lancet. 2012;380:219-29.

2. Hallal PC, Andersen LB, Bull FC, Guthold R, Haskell W, Ekelund U, et al. Global physical activity levels: surveillance progress, pitfalls, and prospects. Lancet. 2012;380:247-57.

3. Heath GW, Parra DC, Sarmiento OL, Andersen LB, Owen N, Goenka S, et al. Evidence-based intervention in physical activity: lessons from around the world. Lancet. 2012;380:272-81.

4. Glasgow RE, Emmons KM. How can we increase translation of research into practice? Types of evidence needed. Annu Rev Publ Health. 2007;28:413-33.

5. Gagliardi AR, Faulkner G, Ciliska D, Hicks A: Factors contributing to the effectiveness of physical activity counselling in primary care: A realist systematic review. Patient Educ Couns 2014:98(4):412-9.

6. Orrow G, Kinmonth AL, Sanderson S, Sutton S. Republished research: effectiveness of physical activity promotion based in primary care: systematic review and meta-analysis of randomised controlled trials. $\mathrm{Br} J$ Sports Med. 2013:47:27.

7. Orrow G, Kinmonth AL, Sanderson S, Sutton S. Effectiveness of physical activity promotion based in primary care: systematic review and metaanalysis of randomised controlled trials. BMJ. 2012;344:e1389.

8. Wu S, Cohen D, Shi Y, Pearson M, Sturm R. Economic analysis of physical activity interventions. Am J Prev Med. 2011;40:149-58.

9. Garrett S, Elley CR, Rose SB, O'Dea D, Lawton BA, Dowell AC. Are physical activity interventions in primary care and the community cost-effective? A systematic review of the evidence. Br J Gen Pract. 2011;61:e125-133.

10. Broekhuizen K, Kroeze W, van Poppel MN, Oenema A, Brug J. A systematic review of randomized controlled trials on the effectiveness of computertailored physical activity and dietary behavior promotion programs: an update. Ann Behav Med. 2012;44:259-86.
11. Lustria ML, Noar SM, Cortese J, Van Stee SK, Glueckauf RL, Lee J. A metaanalysis of web-delivered tailored health behavior change interventions. J Health Commun. 2013;18:1039-69.

12. Enwald HP, Huotari ML. Preventing the obesity epidemic by second generation tailored health communication: an interdisciplinary review. J Med Internet Res. 2010;12:e24.

13. del Hoyo-Barbolla E, Kukafka R, Arredondo MT, Ortega M. A new perspective in the promotion of e-health. Stud Health Technol Inform. 2006;124:404-12.

14. Peels DA, Bolman C, Golsteijn RH, De Vries H, Mudde AN, van Stralen MM, et al. Differences in reach and attrition between Web-based and printdelivered tailored interventions among adults over 50 years of age: clustered randomized trial. J Med Internet Res. 2012;14:e179.

15. Davies CA, Spence JC, Vandelanotte C, Caperchione CM, Mummery WK. Meta-analysis of internet-delivered interventions to increase physical activity levels. Int J Behav Nutr Phys Act. 2012;9:52.

16. Joseph RP, Durant NH, Benitez TJ, Pekmezi DW. Internet-based physical activity interventions. Am J Lifestyle Med. 2014:8:42-68.

17. Laplante C, Peng W. A systematic review of e-health interventions for physical activity: an analysis of study design, intervention characteristics, and outcomes. Telemed J E Health. 2011;17:509-23.

18. Bagoien TE, Halvari $\mathrm{H}$, Nesheim $\mathrm{H}$. Self-determined motivation in physical education and its links to motivation for leisure-time physical activity, physical activity, and well-being in general. Percept Mot Skills. 2010;111:407-32

19. Silva MN, Markland D, Carraca EV, Vieira PN, Coutinho SR, Minderico CS, et al. Exercise autonomous motivation predicts 3-yr weight loss in women. Med Sci Sports Exerc. 2011;43:728-37.

20. Sweet SN, Fortier MS, Guerin E, Tulloch H, Sigal RJ, Kenny GP, et al. Understanding physical activity in adults with type 2 diabetes after completing an exercise intervention trial: a mediation model of self-efficacy and autonomous motivation. Psychol Health Med. 2009;14:419-29.

21. Sebire SJ, Standage M, Vansteenkiste M. Predicting objectively assessed physical activity from the content and regulation of exercise goals: evidence for a mediational model. J Sport Exerc Psychol. 2011;33:175-97.

22. Teixeira PJ, Carraca EV, Markland D, Silva MN, Ryan RM. Exercise, physical activity, and self-determination theory: a systematic review. Int J Behav Nutr Phys Act. 2012;9:78.

23. Miller WR, Rollnick S. Motivational interviewing. Helping people change. New York, NY: The Guilford Press; 2013.

24. Ryan RM, Deci EL. Self-determination theory and the facilitation of intrinsic motivation, social development, and well-being. Am Psychol. 2000:55:68-78.

25. Patrick H, Canevello A. Methodological overview of a self-determination theory-based computerized intervention to promote leisure-time physical activity. Psychol Sport Exerc. 2011;12:13-9.

26. Friederichs SA, Oenema A, Bolman C, Guyaux J, van Keulen HM, Lechner L. I Move: systematic development of a web-based computer tailored physical activity intervention, based on motivational interviewing and selfdetermination theory. BMC Public Health. 2014;14:212.

27. Deci EL, Ryan RM. Self-determination theory: a macrotheory of human motivation, development, and health. Can Psychol. 2008;49:182-5.

28. Ryan RM, Patrick H, Deci EL, Williams GC. Facilitating health behaviour change and its maintenance: Intreventions based on Self-Detyermination Theory. Eur Health Psychol. 2008;10:2-5.

29. Patrick H, Resnicow K, Teixeira PJ, Williams GC. Communication skills to elicit physical activity behavior change: how to talk to the client. In: Nigg CR, editor. ACSM's behavioral aspects of physical activity and exercise. Philadelphia, PA: Lippincott Williams \& Wilkins; 2013.

30. Markland D, Ingledew DK. Exercise participation motives. In: Hagger MS, Chatzisarantis NL, editors. Intrinsic motivation and self-determination in exercise and sport. Champaign, IL: Human Kinetics; 2007. p. 23-34.

31. Patrick H, Williams GC. Self-determination theory: its application to health behavior and complementarity with motivational interviewing. Int J Behav Nutr Phys Act. 2012:9:18.

32. Markland D, Ryan RM, Tobin VJ, Rollnick S. Motivational interviewing and self-determination theory. J Soc Clin Psychol. 2005;24:811-31.

33. Vansteenkiste M, Williams GC, Resnicow K. Toward systematic integration between Self-Determination Theory and Motivational Interviewing as examples of top-down and bottom-up intervention development: Autonomy or volition as a fundamental theoretical principle. Int J Behav Nutr Phys Act. 2012;9:23 
34. Van Hoecke AS, Delecluse C, Opdenacker J, Lipkens L, Martien S, Boen F. Long-term effectiveness and mediators of a need-supportive physical activity coaching among Flemish sedentary employees. Health Promot Int. 2013:28:407-17.

35. Van Hoecke AS, Delecluse C, Bogaerts A, Boen F. The long-term effectiveness of need-supportive physical activity counseling compared with a standard referral in sedentary older adults. J Aging Phys Act. 2014:22:186-98.

36. Silva MN, Markland D, Minderico CS, Vieira PN, Castro MM, Coutinho SR, et al. A randomized controlled trial to evaluate self-determination theory for exercise adherence and weight control: rationale and intervention description. BMC Public Health. 2008;8:234.

37. Silva MN, Markland D, Vieira PN, Coutinho SR, Carraça EV, Palmeira AL, et al Helping overweight women become more active: Need support and motivational regulations for different forms of physical activity. Psychol Sport Exerc. 2010;11:591-601.

38. Silva MN, Vieira PN, Coutinho SR, Minderico CS, Matos MG, Sardinha LB, et al. Using self-determination theory to promote physical activity and weight control: a randomized controlled trial in women. J Behav Med. 2010;33:11022.

39. Duda JL, Williams GC, Ntoumanis N, Daley A, Eves FF, Mutrie N, et al. Effects of a standard provision versus an autonomy supportive exercise referral programme on physical activity, quality of life and well-being indicators: a cluster randomised controlled trial. Int J Behav Nutr Phys Act. 2014;11:10.

40. Jolly K, Duda JL, Daley A, Eves FF, Mutrie N, Ntoumanis N, et al. Evaluation of a standard provision versus an autonomy promotive exercise referral programme: rationale and study design. BMC Public Health. 2009;9:176.

41. Fortier MS, Duda JL, Guerin E, Teixeira PJ. Promoting physical activity: development and testing of self-determination theory-based interventions. Int J Behav Nutr Phys Act. 2012;9:20.

42. Fortier MS, Hogg W, O'Sullivan TL, Blanchard C, Reid RD, Sigal RJ, et al. The physical activity counselling (PAC) randomized controlled trial: rationale, methods, and interventions. Appl Physiol Nutr Metab. 2007;32:1170-85.

43. Fortier MS, Hogg W, O'Sullivan TL, Blanchard C, Sigal RJ, Reid RD, et al. Impact of integrating a physical activity counsellor into the primary health care team: physical activity and health outcomes of the Physical Activity Counselling randomized controlled trial. Appl Physiol Nutr Metab. 2011:36:503-14

44. van Stralen MM, de Vries H, Bolman C, Mudde AN, Lechner L. Exploring the efficacy and moderators of two computer-tailored physical activity interventions for older adults: a randomized controlled trial. Ann Behav Med. 2010;39:139-50

45. Peels DA, van Stralen MM, Bolman C, Golsteijn RH, de Vries H, Mudde AN, et al. The differentiated effectiveness of a printed versus a Web-based tailored physical activity intervention among adults aged over 50 . Health Educ Res. 2014;29:870-82.

46. Peels DA, de Vries H, Bolman C, Golsteijn RH, van Stralen MM, Mudde AN, et al. Differences in the use and appreciation of a web-based or printed computer-tailored physical activity intervention for people aged over 50 years. Health Educ Res. 2013;28:715-31.

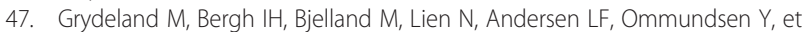
al. Intervention effects on physical activity: the HEIA study - a cluster randomized controlled trial. Int J Behav Nutr Phys Act. 2013;10:17-7.

48. Marcus BH, Napolitano MA, King AC, Lewis BA, Whiteley JA, Albrecht A, et al. Telephone versus print delivery of an individualized motivationally tailored physical activity intervention: Project STRIDE. Health Psychol. 2007;26:401-9.

49. Smeets T, Brug J, de Vries H. Effects of tailoring health messages on physical activity. Health Educ Res. 2008;23:402-13.

50. Vandelanotte C, De Bourdeaudhuij I, Sallis JF, Spittaels H, Brug J. Efficacy of sequential or simultaneous interactive computer-tailored interventions for increasing physical activity and decreasing fat intake. Ann Behav Med. 2005;29:138-46.

51. Smeets T, Kremers SP, Brug J, de Vries H. Effects of tailored feedback on multiple health behaviors. Ann Behav Med. 2007;33:117-23.

52. Cook TL, De Bourdeaudhuij I, Maes L, Haerens L, Grammatikaki E, Widhalm $K$, et al. Moderators of the effectiveness of a web-based tailored intervention promoting physical activity in adolescents: the HELENA Activ-O-Meter. J Sch Health. 2014;84:256-66.

53. Friederichs S, Bolman C, Oenema A, Guyaux J, Lechner L. Motivational interviewing in a web-based physical activity intervention with an avatar: randomized controlled trial. J Med Internet Res. 2014;16:e48.
54. Friederichs SA, Oenema A, Bolman C, Guyaux J, van Keulen HM, Lechner L: Motivational interviewing in a web-based physical activity intervention: questions and reflections. Health Promot Int 2013. Epub ahead of print.

55. Elfeddali I, Bolman C, Candel MJ, Wiers RW, de Vries H. Preventing smoking relapse via Web-based computer-tailored feedback: a randomized controlled trial. J Med Internet Res. 2012;14:e109.

56. Peels DA, Bolman C, Golsteijn RH, de Vries H, Mudde AN, van Stralen MM, et al. Long-term efficacy of a printed or a Web-based tailored physical activity intervention among older adults. Int J Behav Nutr Phys Act. 2013;10:104.

57. Peels DA, van Stralen MM, Bolman C, Golsteijn RH, de Vries H, Mudde AN, et al. Development of web-based computer-tailored advice to promote physical activity among people older than 50 years. J Med Internet Res. 2012;14:e39.

58. van Stralen MM, Kok G, de Vries H, Mudde AN, Bolman C, Lechner L. The Active plus protocol: systematic development of two theory- and evidencebased tailored physical activity interventions for the over-fifties. BMC Public Health. 2008:8:399.

59. Robroek SJ, van Lenthe FJ, van Empelen P, Burdorf A. Determinants of participation in worksite health promotion programmes: a systematic review. Int J Behav Nutr Phys Act. 2009;6:26.

60. Brug J, Oenema A, Ferreira I. Theory, evidence and Intervention Mapping to improve behavior nutrition and physical activity interventions. Int J Behav Nutr Phys Act. 2005;2:2.

61. Bartholomew LK, Parcel GS, Kok G, Gottlieb NH, Fernandez ME. Planning health promotion programs: an intervention mapping approach. San Francisco, CA: Jossey-Bass; 2011

62. Wendel-Vos GC, Schuit AJ, Saris WH, Kromhout D. Reproducibility and relative validity of the short questionnaire to assess health-enhancing physical activity. J Clin Epidemiol. 2003;56:1163-9.

63. Helmerhorst HJ, Brage S, Warren J, Besson H, Ekelund U. A systematic review of reliability and objective criterion-related validity of physical activity questionnaires. Int J Behav Nutr Phys Act. 2012;9:103.

64. Milton K, Bull FC, Bauman A. Reliability and validity testing of a single-item physical activity measure. Br J Sports Med. 2011;45:203-8.

65. Milton K, Clemes S, Bull F. Can a single question provide an accurate measure of physical activity? Br J Sports Med. 2013;47:44-8.

66. Wanner M, Probst-Hensch N, Kriemler S, Meier F, Bauman A, Martin BW: What physical activity surveillance needs: validity of a single-item questionnaire. Br J Sports Med 2013;48(21):1570-6.

67. van Poppel MN, Chinapaw MJ, Mokkink LB, van Mechelen W, Terwee CB. Physical activity questionnaires for adults: a systematic review of measurement properties. Sports Med. 2010;40:565-600.

68. Twisk JWR. Applied longitudinal data analysis for epidemiology. New York, NY: Cambridge University Press; 2013

69. Lipsey MW, Wilson D. Practical meta-analysis. CA, Thousand Oaks: SAGE Publications; 2000

70. Rossi JS: Comparison of the use of significance testing and effect sizes in theory-based health promotion research. In 43rd Annual Meeting of the Society for Multivariate Experimental Psychology. Keystone, CO; 2003.

71. van der Horst K, Kremers S, Ferreira I, Singh A, Oenema A, Brug J. Perceived parenting style and practices and the consumption of sugar-sweetened beverages by adolescents. Health Educ Res. 2007;22:295-304.

72. Groeneveld IF, Proper KI, van der Beek AJ, Hildebrandt VH, van Mechelen W. Short and long term effects of a lifestyle intervention for construction workers at risk for cardiovascular disease: a randomized controlled trial. BMC Public Health. 2011;11:836.

73. Rosnow RL, Rosenthal R. Statistical procedures and the justification of knowledge in psychological science. Am Psychol. 1989;44:1276-84.

74. Rodenburg G, Kremers SP, Oenema A, van de Mheen D. Associations of parental feeding styles with child snacking behaviour and weight in the context of general parenting. Public Health Nutr. 2014;17:960-9.

75. Rodenburg G, Oenema A, Kremers SP, van de Mheen D. Parental and child fruit consumption in the context of general parenting, parental education and ethnic background. Appetite. 2012;58:364-72.

76. Eysenbach G. The law of attrition. J Med Internet Res. 2005;7:e11.

77. Crutzen R, Viechtbauer W, Spigt M, Kotz D. Differential attrition in health behaviour change trials: a systematic review and meta-analysis. Psychol Health. 2015;30:122-34

78. Prince SA, Adamo KB, Hamel ME, Hardt J, Connor Gorber S, Tremblay M. A comparison of direct versus self-report measures for assessing physical activity in adults: a systematic review. Int J Behav Nutr Phys Act. 2008;5:56. 
79. Brouwer W, Kroeze W, Crutzen R, de Nooijer J, de Vries NK, Brug J, et al. Which intervention characteristics are related to more exposure to internetdelivered healthy lifestyle promotion interventions? A systematic review. J Med Internet Res. 2011;13:e2.

80. Lyons EJ, Lewis ZH, Mayrsohn BG, Rowland JL. Behavior change techniques implemented in electronic lifestyle activity monitors: a systematic content analysis. J Med Internet Res. 2014;16:e192.

81. Trost SG, O'Neil M. Clinical use of objective measures of physical activity. Br J Sports Med. 2014;48:178-81.

\section{Submit your next manuscript to BioMed Central} and take full advantage of:

- Convenient online submission

- Thorough peer review

- No space constraints or color figure charges

- Immediate publication on acceptance

- Inclusion in PubMed, CAS, Scopus and Google Scholar

- Research which is freely available for redistribution 